\title{
Occupational Health-Items on the Research Agenda
}

\author{
Akizumi Tsutsumi \\ Published online: 20 October 2011 \\ (C) International Society of Behavioral Medicine 2011
}

Occupational health and the well-being of working people are crucial prerequisites for productivity and are of utmost importance for overall socioeconomic and sustainable development [1]. To realize occupational health, a broad research agenda in behavioral medicine needs to be addressed. This issue of International Journal of Behavioral Medicine addresses five relevant topics on this research agenda.

Overtime work is one of the most prevalent healthdamaging factors in the current industrial world, and research is needed on the pathways from work stress and overtime work to illness [2]. There are several factors that are associated with overtime work, from socioeconomic factors to individual coping behaviors. Tairs et al. tested whether overtime work affected workers' health behaviors in their two-wave prospective study [3]. Their hypotheses were partially supported. Working overtime was longitudinally related with adverse subjective health and lower levels of beneficial health behaviors (physical activity and fruit/ vegetables intakes), but not with body weight gain nor with harmful health behaviors (smoking and alcohol drinking). Their structural equation analysis revealed that overtime work was indirectly related with lower levels of subjective health through the health behaviors. A weakness of this study, aimed at measuring health effects of overtime, is that most of the participants did not work overtime at all and those who did only spent moderate amount of time on working overtime, and as the authors noted, to elucidate the true mediation mechanism, three waves or more data are needed. However, this study prospects that further inves-

A. Tsutsumi $(\bowtie)$

Occupational Health Training Center,

University of Occupational and Environmental Health Japan, Kitakyushu, Japan

e-mail: tsutsumi@med.uoeh-u.ac.jp tigations in other diverse working population will provide more definitive evidence on the research questions.

Van Wijhe et al. examined the differences between workaholism and work engagement via affect and the underlying motivation to continue or stop a task [4]. As the health consequences are different, it is justifiable to draw a distinction between workaholism and work engagement. The elucidation of the mechanisms of workaholics and work engaged employees to stop working or continue to work would provide a clue to prevent overtime work which causes health damages. The trial of Van Wijhe et al. was an application of the mood as input model and showed that "mood and persistent rules" may be relevant to distinguish workaholism and work engagement. As with stress reduction, the most promising approaches to modify such a behavioral pattern are cognitive-behavioral ones [5], and current evidence acknowledges their effectiveness [6]. The present study may also imply that multifacet interventional approaches including cognitive-behavioral procedures may be a good option to modify workaholism as well as socioenvironmental strategies (i.e., regulation).

Mechanisms through which job stress is ameliorated or exaggerated are also an important research agenda of this field to countermeasure job stress. It has been hypothesized that stress-buffering effects of job resources would be maximized when job resources are matched to job demands (matching hypothesis). Van den Tooren et al. tried to confirm this study hypothesis using their two-wave longitudinal survey of 317 beginning teachers [7]. Interestingly, their results indicate that there seems no difference whether or not specific types of job demands and job resources are matched, and whether or not individual differences in specific active coping styles are taken into account to show stress-buffering effects of job resources. The reasons of negative findings were discussed in terms of the study 
population (who just started their employed life) and stronger impact of job characteristics than personal characteristics on job stress process, and mere perception of having resources, irrespective of the specific types, may offset the impact of job demands. Despite that the study hypothesis were not totally supported, it shows that matching specific types of job demands and job resources in order to show stress-buffering effects is a valuable way of working [8], and further studies are necessary.

With regard to the impact of occupational health hazard, the physician is one of the most important target populations [9]. Compared with the general working population, depression is more prevalent among physicians [10]. Because mental disorders of physicians may impair patient care, a high prevalence of depression evolves as a social issue [11]. Wada et al. showed a high prevalence of unreasonable patient demands and complaints experienced by Japanese physicians and significant associations with depression and suicidal ideation in their nationwide survey of physicians [12]. This is an important topic, especially in terms of increasing demands, an aging population, and limited resources among physicians. From the perspective of occupational health, an organizational approach at the hospital is the first approach to countermeasure the health damages of physicians. Additionally, behaviors of the patients and the underlying doctor-patient relationship would be interesting research topics.

Development of psychosocial scales is an important research agenda and is within the scope of International Journal of Behavioral Medicine. Based on a national survey of employees in Taiwan, Cheng et al. displayed the validity of newly developed multi-item scales for the assessment of employment insecurity and workplace justice and the associations between employment insecurity, workplace justice, and burnout in Taiwanese employees [13]. Employment insecurity has drawn less attention compared to job insecurity, but employment insecurity, the likelihood of being able to remain in paid employment in the labor market, may be prevalent among less privileged employees in the era of globalization [14]. Although more refinements seem needed, the developed scale using a representative sample of paid employees in Taiwan has the potential to provide useful information across socioeconomic strata or across cultures, in particular on employees in smallsized enterprises.

In sum, the five studies of the present issue of International Journal of Behavioral Medicine not only add much to the present literature on occupational health but also inspire readers to carry on their own studies addressing issues on this important research agenda.

\section{References}

1. WHO. Global strategy on occupational health for all: the way to health at work. Geneva: WHO; 1995 [cited 2011 Sept 17]. http:// www.who.int/occupational_health/en/oehstrategy.pdf. Accessed 17 Sept 2011.

2. Härmä M. Workhours in relation to work stress, recovery and health. Scand J Work Environ Heal. 2006;32(6):502-14.

3. Taris TW, Ybema JF, Beckers DG, Verheijden MW, Geurts SA, Kompier MA. Investigating the associations among overtime work, health behaviors, and health: a longitudinal study among full-time employees. Int J Behav Med. 2011. doi:10.1007/s12529-010-9103-z.

4. Van Wijhe CI, Peeters MC, Schaufeli WB. To stop or not to stop, that's the question: about persistence and mood of workaholics and work engaged employees. Int J Behav Med. 2011. doi:10.1007/s12529-011-9143-z.

5. Roskies A. Stress management for the healthy Type A: theory and practice. New York: Guilford Press; 1987.

6. van der Klink JJL, Blonk RWB, Schene AH, van Dijk FJH. The benefits of interventions for work-related stress. Am J Public Health. 2001;91(2):270-6.

7. van den Tooren M, de Jonge J, Vlerick P, Daniels K, Van de Ven B. Job resources and matching active coping styles as moderators of the longitudinal relation between job demands and job strain. Int J Behav Med. 2011. doi:10.1007/s12529-011-9148-7.

8. de Jonge J, Dormann C. The DISC model: demand-induced strain compensation mechanisms in job stress. In: Dollard MF, Winefield HR, Winfefield AH, editors. Occupational stress in the service professions. London: Taylor \& Francis; 2003. p. 43-74.

9. Myers MF, Gabbard GO. The physician as patient: a clinical handbook for mental health professionals. Arlington: American Psychiatric Publishing; 2008.

10. Bazargan M, Makar M, Bazargan-Hejazi S, Ani C, Wolf KE. Preventive, lifestyle, and personal health behaviors among physicians. Acad Psychiatry. 2009;33(4):289-95.

11. Center C, Davis M, Detre T, Ford DE, Hansbrough W, Hendin H, et al. Confronting depression and suicide in physicians: a consensus statement. JAMA. 2003;289(23):3161-6.

12. Wada K, Yoshikawa T, Goto T, Hirai A, Matsushima E, Nakashima Y, et al. Association of depression and suicidal ideation with unreasonable patient demands and complaints among Japanese physicians: a national cross-sectional survey. Int J Behav Med. 2010. doi:10.1007/s12529-010-9132-7.

13. Cheng Y, Huang HY, Li PR, Hsu JH. Employment insecurity, workplace justice and employees' burnout in Taiwanese employees: a validation study. Int $\mathrm{J}$ Behav Med. 2011. doi:10.1007/ s12529-011-9152-y.

14. Ostry AS, Spiegel JM. Labor markets and employment insecurity: impacts of globalization on service and healthcare-sector workforces. Int J Occup Environ Health. 2004;10(4):368-74. 